\title{
Increased personal protective equipment litter as a result of COVID-19 measures
}

\author{
Keiron P. Roberts $\oplus^{1 凶}$, Sui C. Phang $\oplus^{2,7}$, John B. Williams ${ }^{1}$ ', David J. Hutchinson ${ }^{(1}$, \\ Simon E. Kolstoe $\mathbb{C}^{3}$, Jasper de Bie ${ }^{4}$, lan D. Williams $\mathbb{1}^{5}$ and Anne M. Stringfellow ${ }^{6}$
}

\begin{abstract}
Use of personal protective equipment (PPE) increased during the COVID-19 pandemic to reduce virus transmission. Here, we quantitatively analyse emergence of PPE and COVID-19-related litter over 14 months for 11 countries using the litter collection application Litterati. The proportion of masks in litter increased by $>80$-fold as a result of COVID-19 legislation, from $<0.01 \%$ to $>0.8 \%$. Gloves and wipes, more prevalent at $\sim 0.2 \%$ of litter before the pandemic, doubled to $0.4 \%$, but this has since fallen. Glove litter increased in the initial stages of the pandemic but fell after the introduction of facemask policies, whereupon there was an increase of facemask litter. National COVID-19 policy responses and international World Health Organization announcements and recommendations are a probable driver of PPE litter dynamics, especially the implementation of facemask policies. Waste management should be incorporated in designing future pandemic policies to avoid negative environmental legacies of mismanaged PPE.
\end{abstract}

$\mathrm{P}$ ublic attention during the COVID-19 pandemic has understandably focused on human health but there is now evidence that society's response is leading to environmental impacts that will last well beyond the pandemic ${ }^{1,2}$. Since the World Health Organization (WHO) announced a global health emergency on 30 January 2020, there has been an unprecedented increase in demand and use of personal protective equipment (PPE) to reduce virus transmission ${ }^{3}$. Nations and regions have adopted different policy responses to the use of social or physical distancing measures and the wearing of masks or face coverings (herein referred to collectively as masks) within their populations. Most authorities instigated restrictions on workplaces within days of the WHO announcement, with national guidance on mask use generally announced around the same time as the WHO advice. However, masks and other PPE items are increasingly found as litter ${ }^{4,5}$ and the use of materials such as plastic in these items represents a global environmental challenge ${ }^{6}$.

PPE is used by health professionals to prevent infection and contamination, and when required in non-medical workplaces (for example, construction, carpentry, painting and decorating, laboratories and food processing $)^{7,8}$. These are often single-use items manufactured from polymeric materials designed to be disposed of within either medical/hazardous or general waste depending on their level of contamination ${ }^{9,10}$. Within certain regions there has been a socially established practice of wearing masks in non-medical settings to help prevent the spread of infection ${ }^{11}$ with their main purpose to serve as 'source control' ${ }^{12-14}$.

Throughout the initial stages of the pandemic (February to May 2020), anecdotal reports emerged of increased littering of masks and personal cleaning products such as wipes (for example, disinfectant wipes/wet wipes) and gloves s, $9,15-17^{\text {. Restrictions on movements }}$ across the globe (lockdowns) presented challenges for scientists in quantifying the reported environmental impacts of COVID19-related litter including the potential impact of policies. We have therefore used data collected by the public before and during the pandemic to enable an analysis of changes in behaviours during the initial stages of the pandemic ${ }^{4,18-21}$. Pre-pandemic waste management practices and infrastructure were predominate throughout the initial months of the pandemic, resulting in difficulties in waste treatment/collection ${ }^{10,22}$. Increasing concern about the potential health and environmental impacts of mismanaged PPE began to increase after the pandemic announcement ${ }^{4,23,24}$

To investigate the changing patterns of PPE litter during a pandemic, we present a multicountry analysis of the emergence of COVID-19-related litter and relate it to timings of national policies and WHO recommendations for 11 nations (Australia, Belgium, Canada, France, Germany, the Netherlands, New Zealand, Spain, Sweden, the United Kingdom and the United States). First, we report the time series observations from September 2019 to the end of October 2020 from citizen science data on the presence of key COVID-19-related litter of masks, gloves and wipes at national and international scales. Second, we correlate these patterns to the timing of international pandemic announcements from the WHO and national-level mask and lockdown regulations to identify pandemic-related policies on the presence of PPE in litter.

\section{Results}

The emergence of COVID-19-related litter. Our method used existing data within the crowd-based, citizen science application Litterati to enable an analysis of littering behaviour and the proportional composition of COVID-19-related litter ${ }^{18}$. These applications enable a rapid collection of data across a dispersed environment without compromising data quality and, in this instance, enabled retrospective analysis of collected data ${ }^{23,25,26}$. This allowed the observation of phenomena and collection of data on scales previously restricted to localized case studies or requiring substantial investment in research methodologies ${ }^{19}$. Litterati was selected for its temporal and geographic coverage, preventing possible double

'School of Civil Engineering \& Surveying, University of Portsmouth, Portsmouth, UK. ${ }^{2}$ Centre for Blue Governance, University of Portsmouth, Portsmouth, UK. ${ }^{3}$ School of Health and Care Professions, University of Portsmouth, Portsmouth, UK. ${ }^{4}$ Coastal and Marine Research Centre, Griffith University, Southport, Queensland, Australia. ${ }^{5}$ Faculty of Engineering \& Physical Sciences, University of Southampton, Southampton, UK. ${ }^{6} \mathrm{Civil} \&$ Environmental Engineering, University of Southampton, Southampton, UK. ${ }^{7}$ Present address: The Nature Conservancy, London, UK. 凶e-mail: Keiron.Roberts@port.ac.uk 

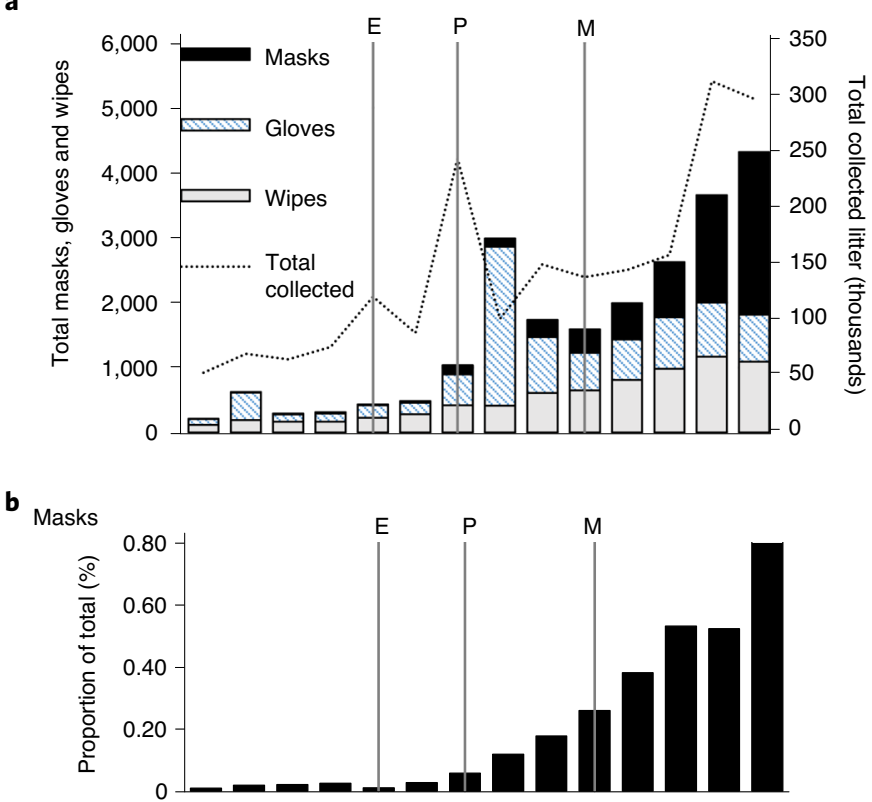

c

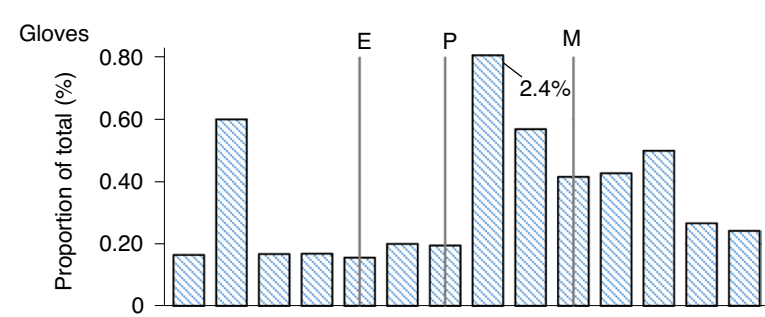

d

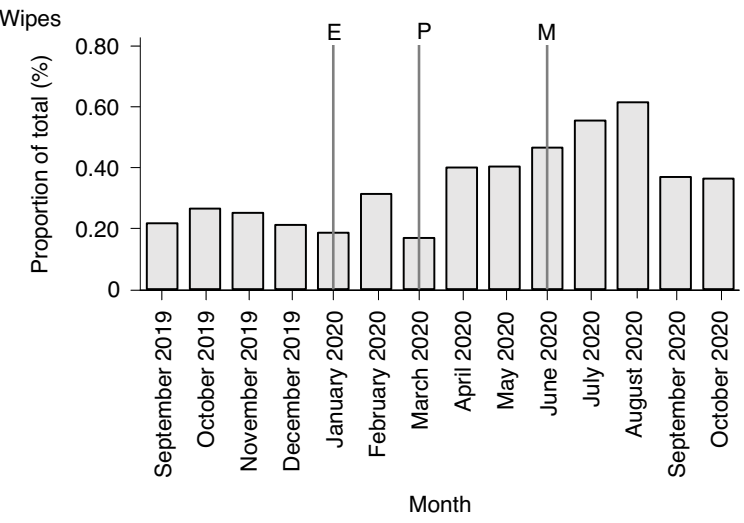

Fig. 1 | Total collected litter per month for all countries analysed and total proportion of masks, gloves and wipes of the total collected litter. a, Total collected litter refers to all litter tagged with total counts for masks, gloves and wipes. b-d, Masks (b), gloves (c) and wipes (d) as proportions of the total collected litter. Vertical grey lines denote the month of the WHO declarations and guidance: $E$, emergency; $P$, pandemic; and $M$, general mask use recommended.

counting if other additional litter debris applications were used. The data analysed here cover the period September 2019 (6 months before the pandemic announcement) to October 2020. Items were classified as: (1) masks, (2) gloves and (3) wipes (Fig. 1). This general classification was used due to complexity of littered items tags (in excess of 90,000).

In the 4 months before the WHO announced a health emergency (Fig. 1) the quantities of masks, gloves and wipes collected remained stable with the proportion of masks at $<0.01 \%$ and gloves and wipes at $\sim 0.2 \%$. After the announcement of the pandemic there was an increase of all PPE types examined. Gloves show an initial spike to $2.4 \%$ from pre-pandemic levels of $\sim 0.2 \%$ but then declining to $\sim 0.4 \%$. Wipes show an initial gradual increase from March to August of $\sim 0.2$ to $0.6 \%$, decreasing to double pre-pandemic levels of $\sim 0.4 \%$. Masks show a linear increase with time $\left(R^{2}=0.937\right)$ from March to October, reaching a peak proportion of $0.84 \%$ of total collected litter. Importantly, these proportions were observed alongside an increase in the total number of litter items recorded in Litterati, indicating that this was not an artefact of sampling.

Littered masks have had the greatest change since the pandemic announcement, with an exponential increase from March 2020, resulting in an 84-fold increase on the previous year by October 2020. An abrupt increase in demand for PPE, particularly masks, resulted in an immediate global supply shortage ${ }^{20,21}$. In March 2020, the WHO estimated an increase in monthly demand for healthcare settings alone of 89 million masks and 76 million gloves ${ }^{21}$. During the initial 6 months of the health emergency, the WHO advised that the general public should not wear masks ${ }^{10,20}$. This guidance was under continual review and it was changed on 5 June 2020 to recommend the general use of masks in settings where social distancing cannot be achieved (for example, public transport) in countries where community transmission was ongoing ${ }^{22}$.

National differences in COVID-19-related litter. The pattern of increasing COVID-19-related litter was not universal and there are clear country-specific differences (Fig. 2). Before the declaration of a pandemic, masks were effectively non-existent as litter for all countries. However, while its presence increased after the WHO declaration, this change differed between countries.

The United Kingdom showed the highest overall proportion of masks, gloves and wipes as litter. For August-October 2020, masks accounted for $>5 \%$ of all litter, with gloves and wipes present at $\sim 1.5 \%$ respectively. Other countries showed different patterns of COVID-19-related litter proportions, with several showing little change before and after the pandemic announcements. In the Netherlands, for example, the proportion of masks, gloves and wipes does not exceed $1 \%$ of the total tagged litter, except for gloves, which reached 3\% in April 2020. Sweden had many months when no COVID-19-related litter was recorded. Canada shows an emergence of mask, glove and wipe litter around and after the announcement of a pandemic, with Germany and the United States having a similar response for masks but gloves and wipes were present as litter before the pandemic.

Intercountry differences in COVID-19-related litter are observed for all litter types examined. The exponential increase in proportion of masks in the United Kingdom matches the general pattern of change (Fig. 2) but its timing was a month behind the WHO's announcement of the pandemic.

The impact of pandemic-related policies on litter. COVID-19 emerged and spread rapidly in December 2019, with differing international responses throughout the timespan used in this study (Fig. 3). Time of instigation and severity of these national-level interventions, along with WHO advice, created a complicated variation of conditions for different nations.

The Oxford University Coronavirus Government Response Tracker $^{24}$ categorized government responses on a four-point scale (Methods). While some countries recommended closing and working from home (for example, the United Kingdom and the Netherlands), a typical response has been to require all but essential workplaces to close in favour of home working (level 3 response). Sweden did not implement mandatory closures or the usage of masks throughout the duration of the pandemic (Fig. 3), while Australia and New Zealand only required these in June/July of 2020 


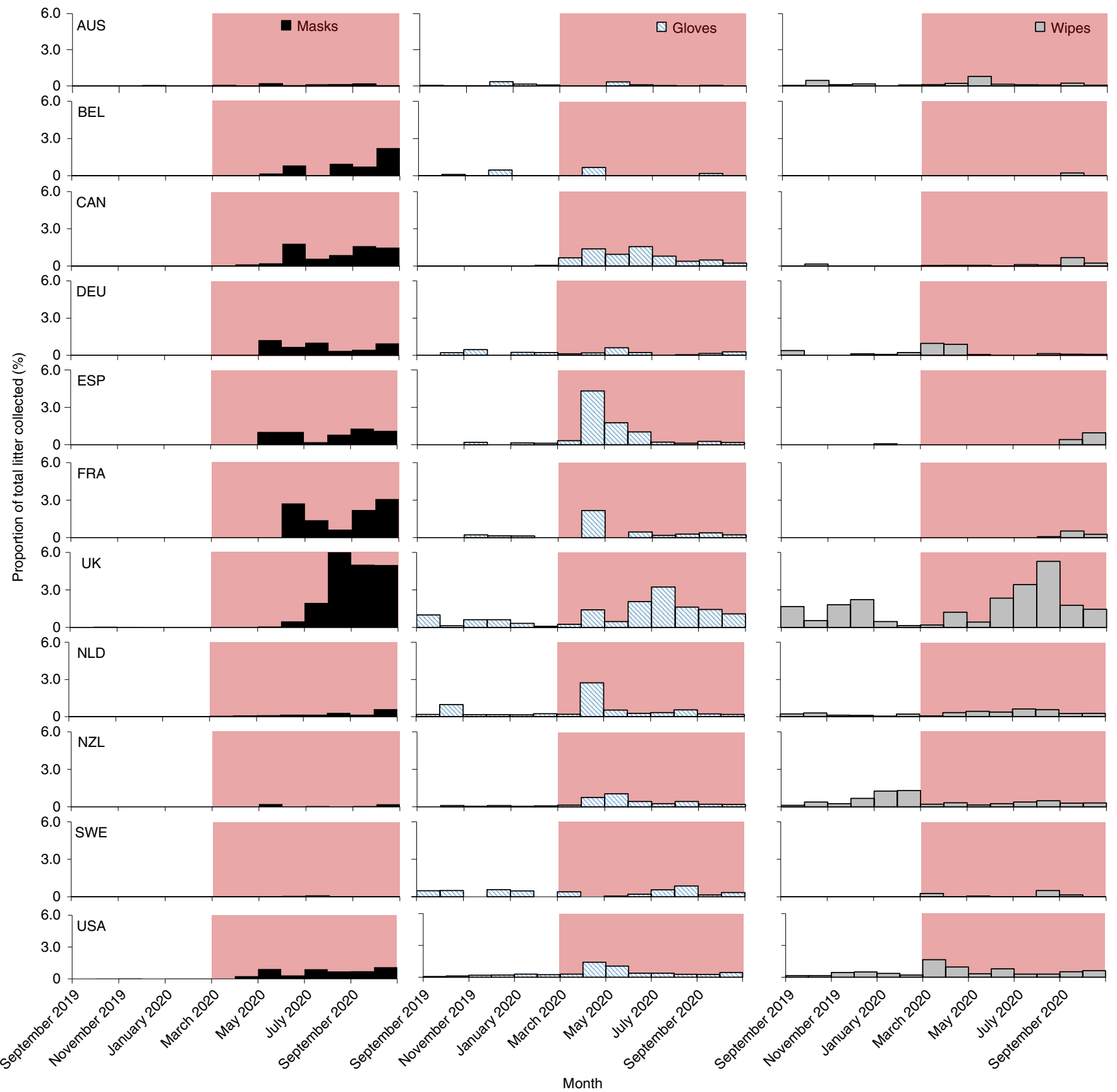

Fig. 2 | The pattern of COVID-19-related litter shows country-specific differences. Proportion of masks (black), gloves (blue) and wipes (grey) for each of the 11 nations. Red shading after March 2020 denotes the period within the pandemic. Country codes: AUS, Australia; BEL, Belgium; CAN, Canada; DEU, Germany; ESP, Spain; FRA, France; UK, United Kingdom; NLD, the Netherlands; NZL, New Zealand; SWE, Sweden; USA, United States.

when new cases rose after the initial response had been largely lifted. As of October 2020, most countries had a level 2 response in place except for Sweden, Australia and New Zealand. The different levels of governmental response, in turn, had unintended consequences in relation to litter composition as has been widely reported ${ }^{15}$.

National policies impact on COVID-19-related litter. The two main types of national policies that we investigated as having potential impacts on COVID-19-related litter were the introduction of mask-wearing policies and 'lockdown' travel restrictions.

The introduction of mask-wearing policies had a clear impact on PPE litter dynamics (Fig. 4). Masks show the greatest response with $\sim 0.01 \%$ on average before legislation but increasing thereafter.
Gloves show an increase 2 months before legislation, instead aligning with the WHO's announcements and advice (Fig. 1) but decreasing after national-level mask-wearing policies. Wipes levels are variable throughout the study period, highlighting the difference in littering behaviours between nations.

For masks and gloves, there were significant differences between the categories following the WHO advice, lockdown level and national mask laws (Kruskal-Wallis tests all $P<0.01$; see Supplementary Table 3 and Fig. 5).

The largest increase in the reported proportions was for masks, with a median increasing from zero to $>0.72 \%$ and national mask legislation appearing to be the most consistent underlying factor (Fig. 5). As nations legislating mask use increased, masks also 
increased as a percentage of litter over time. Compulsory use of masks has a significant impact on wipe littering $(P<0.01)$, whereas gloves show a decrease suggesting other factors are associated with glove littering.

Littered wipes generally show an increase after the declaration of a pandemic (Fig. 1). However, there is no significant response to the timing of the WHO announcements and advice (Fig. 5), suggesting national-level responses had a greater influence on wipe littering. In contrast, gloves showed a significant increase in prevalence with the announcement of the pandemic, which corresponded with most nations' instigation of lockdown level 3. Glove litter prevalence is possibly due to personal actions to prevent surface cross contamination. An increasing awareness and communication of the role of aerosols over the initial months of the pandemic may have shifted the use of PPE away from gloves and towards masks, in line with WHO advice to wear masks, as perhaps evidenced by the increase in mask littering and decrease in glove littering. By lockdown level 2 and the introduction of mask legislation, glove occurrence as litter began to decrease. This may again have been due to an improvement in behaviour or changes in communications about what is required to protect against the virus for the public. Most countries directly entered a level 3 lockdown at the onset of the pandemic in March 2020, which preceded most mask advice and mandates, so this may explain this observation. For wipes, there is an increase in littering occurrence during lockdown level 2, which is potentially due to an increased freedom of movement coupled with the awareness of the need to regularly clean surfaces as opposed to wearing gloves (Fig. 5).

\section{Discussion}

Using citizen science data here allowed us to observe the temporal increase in littered masks, gloves and wipes as a result of national legislation, which would have been missed if these applications were not already in place. Potential sources of error can exist with this research methodology type such as: observer bias, poor and inconsistent tagging of items, lack of standardization of collection methods, regional biases in effort and temporal variation in effort ${ }^{27,28}$. Within this work we have reported at a national level due to the limited granularity of data available. There is potential that biases can occur between high and low population density areas and regions with greater participation. However, citizen science offers increasing access to data that would be complimentary to conventional research capabilities, especially under pandemic travel and work restrictions ${ }^{16,17}$.

We found a global increase in the proportion of COVID19-related litter collected during the initial months of the pandemic. Masks showed the greatest increase and the clearest response to global and national pandemic interventions, increasing from $<0.01$ to $>0.8 \%$ of all litter, a $>80$-fold increase by October 2020. In contrast, gloves and wipes were $\sim 0.2 \%$ before the pandemic announcement, with gloves rising over tenfold and masks threefold in the initial months after the pandemic announcement, before decreasing to $\sim 0.4 \%$ globally by October 2020 . The global WHO advice for public mask wearing had a significant impact on the littering of masks compared to the announcements of an emergency and the pandemic $(P<0.01)$. This coincides with nations reducing their workplace restrictions from the initial higher level of 3 (require closing (or work from home) of all but essential workplaces), to that of 2 (require closing (or work from home) for some businesses), where mask use was used to support social distancing (Fig. 5). The United Kingdom shows a high proportion of mask litter peaking at $6 \%$ when compared to nations with reduced restrictions, such as New Zealand and Australia peaking at $<0.2 \%$ (Fig. 2). Emerging research supports the presence and national variability in COVID19 litter, with one study ${ }^{29}$ reporting a consistent $<1 \%$ composition of COVID-19 litter over a 50-day survey of streets in South Africa. Whereas beach litter surveys in Kenya, 100 days after the first

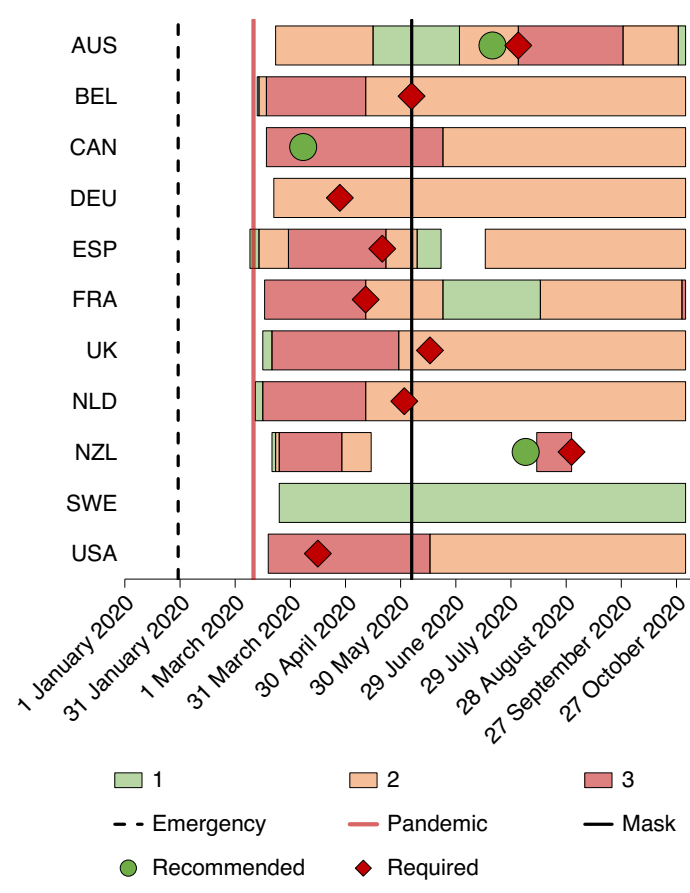

Fig. 3 | Government response to the COVID-19 pandemic. Each bar represents the scale of response: 1 (green), recommend closing (or work from home); 2 (orange), require closing (or work from home) for some businesses (for example, restaurants and theatres); and 3 (red), require closing (or work from home) of all but essential workplaces (for example, grocery stores and doctors). All government responses allowed essential services to remain open. Vertical lines show the WHO declarations and advice for a global emergency, global pandemic and global advice to use masks/coverings. Red diamonds indicate when a country required mask use and green circles indicate when countries recommended mask use.

reported COVID-19 case, showed $16.5 \%$ of litter associated with COVID-19 (includes sanitizer and soap bottles) ${ }^{30}$.

In the initial months of the pandemic, when nations instigated their highest lockdown restrictions, gloves showed the greatest prevalence globally; for example, a survey study ${ }^{4}$ in Toronto Canada found proportionally $44 \%$ gloves, $31 \%$ masks and $25 \%$ wipes in May-June 2020, compared to $42 \%$ gloves, $27 \%$ masks and $31 \%$ wipes. As nations began to reduce lockdown restrictions, incidences of glove littering reduced, probably due to improved education on how the virus is likely to be transmitted, with wipes increasing during lower level restrictions as people begin to clean surfaces.

Estimates of the annual demand for PPE amount to billions of items per country, with the global market increasing in value from US $\$ 800$ million in 2019 to over US\$166 billion in $2020^{14,20,31}$. Estimates for the United Kingdom alone place the general population use at over 24 billion items per year for single-use masks (if reusable ones are not widely used) and an estimated global monthly demand of 129 billion masks and 65 billion gloves ${ }^{6,14}$. Despite multiple vaccines becoming available, a high uptake by the global population will be needed and social distancing measures will need to remain in effect for some time ${ }^{32,33}$. Consequently, it is likely that the use of masks will remain high through 2021 into 2022 and there will be continued mask littering. Wipes and gloves will potentially remain in use whilst there is a high prevalence and transmission of the virus within the community, again with associated littering.

Our results suggest that, alongside addressing the threat to human health, targeted national-level pandemic responses are also necessary to address the threat to environmental health posed by related litter. As it is likely that higher mask use will continue 

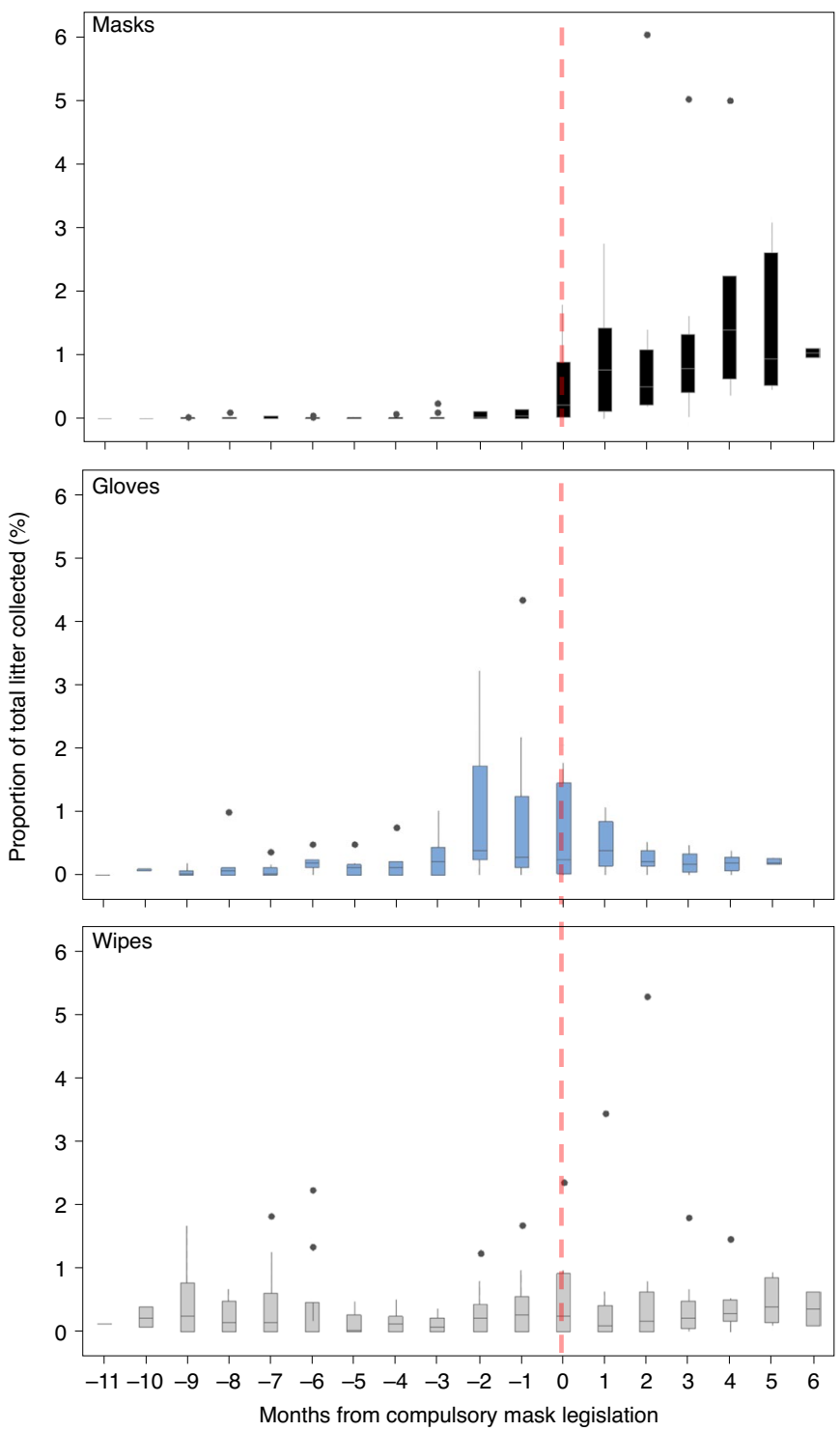

Fig. 4 | Data scaled to the month nations implemented compulsory mask use (month 0 ) for the percentage proportion of masks, gloves and wipes within the total collected litter. Sweden never legislated for mask use and is excluded from this data set. Boxes show interquartile ranges; horizontal lines in boxes are medians; vertical lines are 95\% limits; dots are outliers.

following the immediate health pandemic, such responses must be sustained.

Occurrences of mask, glove and wipe litter has been influenced by the instigation of new legislation requiring the use of masks and the need to clean surfaces and hands (Fig. 5). Differences between nations' mask littering are probably driven by multiple factors including national-level policies, such as mandatory wearing of masks and movement restrictions. The observed variations between nations are complex, with the quantity, composition and distribution dependent on appropriate ISB (infrastructure, service, behaviour) ${ }^{34}$ : (1) infrastructure (for example, convenient and suitably placed litter bins), (2) service provision (for example, street cleansing, litter bin collections, communication materials and enforcement of penalties) and (3) desirable public behaviour (that is, choosing to not litter). Infrastructure and services are typically provided by local/national authorities, although some private companies, especially fast-foods outlets and convenience stores, recognize their role by providing and emptying bins on their property. In terms of behaviour, many surveys have demonstrated that the public are generally aware that it is unacceptable to litter but continue to do so anyway, for a range of reasons, including:

- Personal disposition towards littering (that is, particular and embedded: values, attitudes, knowledge, awareness, personalities, lifestyles, communities, social status and norms)

- Immediate personal circumstances (for example, being drunk, in a rush, a teenager, in someone else's area and unlikely to be seen or caught)

- Factors deemed outside of a person's control (for example, lack of bins in the 'right' places (including inside cars and public transportation), area is already run-down/dirty (so it doesn't matter) or everyone else is doing it)

- 'Beneficial' factors (for example, provides jobs for cleansing staff, revenue raised from fines, provides food for wildlife, food or peels are biodegradable so provide nutrients for soil)

Research has shown that people litter more in already-littered environments $\mathrm{s}^{35}$. During the pandemic, waste collection authorities were under pressure due to staff absence and requirements for new working practices, potentially leading to reduced street cleaning and less frequent collection of waste from litter bins ${ }^{36,37}$. Further research is required to determine if this was a factor in the increase of littering which occurred, particularly after the lifting of strict lockdown periods. The increased proportion of PPE as litter could also point to the public being unprepared to deal with waste PPE outside of their homes. They may be concerned that taking waste home for disposal could potentially contaminate vehicles or shopping bags-therefore littering may appear to present less personal risk if no bins are available.

Our results highlight the impact that legislation can have on the composition of litter. As mentioned, it is likely that PPE litter will persist throughout the pandemic, which can create a series of environmental and health impacts if mitigation is not undertaken.

If littered PPE and cleaning products are allowed to persist in the environment they present hazards to humans, the environment and infrastructure. These impacts are dependent on the duration since an item was littered and the environmental conditions it was deposited into. This can be separated into three categories: short term, medium term and long term.

Short-term impacts. Within the first few hours and days, littered PPE and wipes pose a potential viral vector of COVID-19 if used by an infected person ${ }^{38}$. Littered items create a visual pollutant that can encourage further littering within that area ${ }^{35,39}$.

Littered items can be transported by weather conditions into drains and sewerage systems, creating potential blockages where they entangle with other solids (for example, leaf litter) ${ }^{40,41}$. Where combined sewerage systems are used this can create a direct route from the terrestrial into the marine environment ${ }^{42}$ or into rivers/ streams ${ }^{43}$. Masks are manufactured in a similar way to that of wipes, presenting similar problems in sewerage systems, with the added complication of elastic ties.

Medium-term impacts. For megafauna, there is a risk of choking and entanglement with discarded litter, with the difficulty to mechanically break down the material and the straps/elastic causing entanglement ${ }^{44}$. If ingested, malnourishment can occur whereby non-digestible plastics accumulate impacting survival ${ }^{45,46}$. Where there are high volumes of waste, smothering can occur, whereby organisms experience difficulty surviving and propagating ${ }^{47}$.

Long-term impacts. Once in the environment, littered items can continue to have the impacts mentioned above, with the addition of becoming vectors for other pathogens and pollutants. Chemical, 

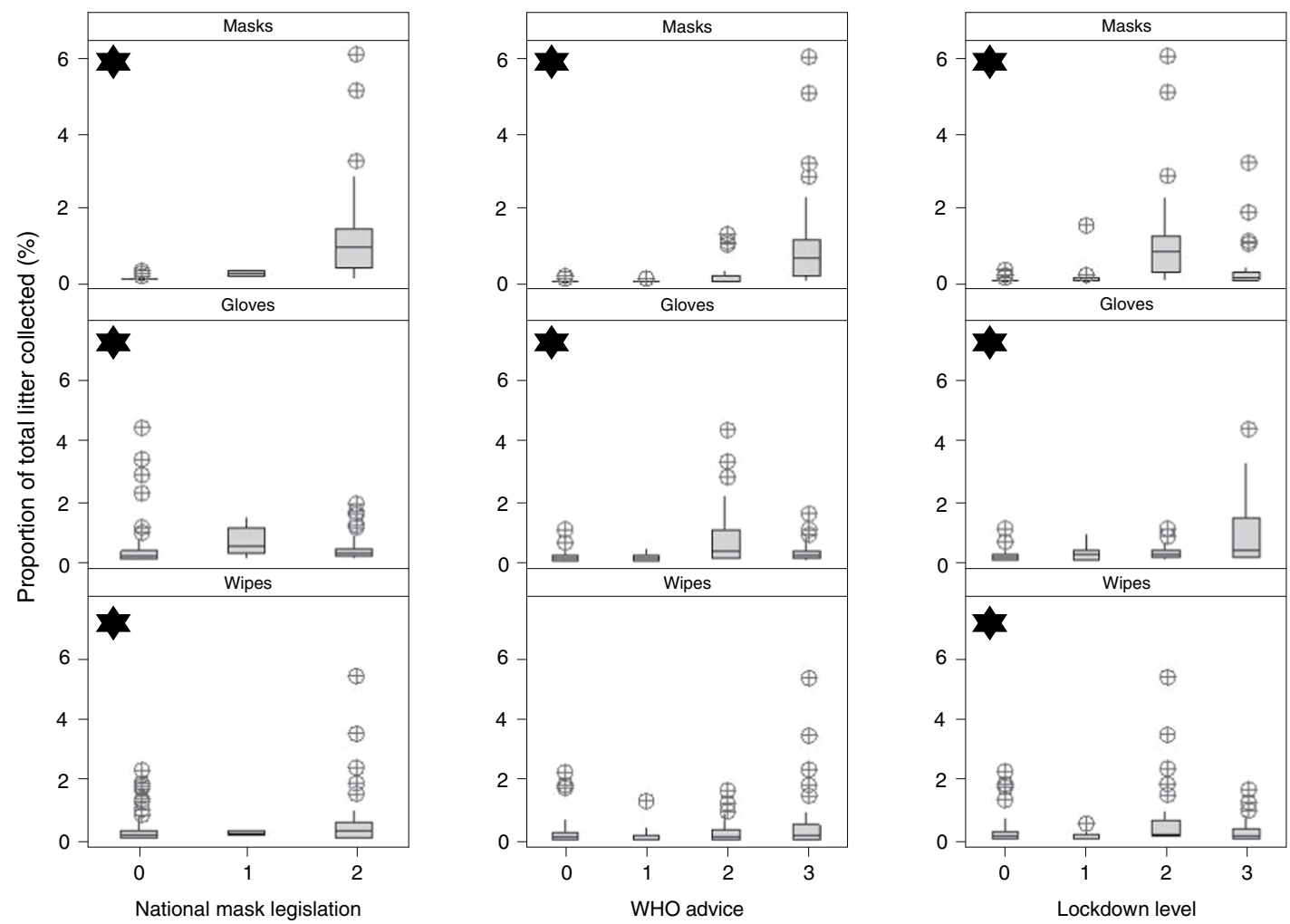

Fig. 5 | Effects of WHO advice, lockdown level and national mask laws on littering of masks, gloves and wipes. Relationship of national mask guidance/ legislation ( 0 , no legislation; 1 , masks recommended; 2 , masks required), workplace lockdown level ( 0 , no lockdown restrictions; 1 , recommend work from home; 2, work from home where possible with some workplaces closed; 3, all non-essential business closed with work from home mandatory) and the $\mathrm{WHO}$ announcements and guidance on the proportion of mask, glove and wipe litter to the total collected. Boxes show interquartile ranges; horizontal lines in boxes are medians; vertical lines are $95 \%$ limits and circles are outliers. A star in the left corner denotes $P<0.05$ (Supplementary Table 3).

physical and biological weathering will break the littered items down from macro-plastics $(>5 \mathrm{~mm})$ into micro-plastics $(<0.5 \mathrm{~mm})$ and nano-plastics $(<100 \mathrm{~nm})$ that have the potential to enter the lower food chain and have toxicological effects including the leaching of metals $s^{9,27,28,48,49}$.

Authorities have been under huge pressure during this pandemic and waste management solutions to address littering of PPE have not been high on their agenda. However, as vaccines emerge and the scale and impacts of littering have become apparent, local and national action is necessary. As highlighted by the ISB model, measures must address all factors that contribute to inadequate waste management, in this case, PPE littering (that is, building appropriate infrastructure and service provision alongside actions to influence appropriate behaviour change $)^{34}$. Such measures are likely to include development of policy, legislation, producer responsibility, improvements in waste management infrastructure (new bins in 'hot spots' for littered PPE) and service provision (more frequent bin emptying), targeted communication campaigns and signage. Preventing the need for single-use PPE, especially masks and gloves, will require greater access to reusable items and guidance on frequency and conditions for safe and suitable washing.

Individual nations' policy and legislation on mask use has required citizens to purchase and use, often for the first time, single-use masks. This has resulted in an increase of mask litter collected from September 2019 to October 2020. Within several countries reported here, this is an increasingly abundant form of litter. All nations that legislated the use of masks saw an increase in the occurrence of mask littering. However, nations have differing littering behaviours regarding masks, with some littering substantially more than others. This study supports the anecdotal accounts of
COVID-19-related litter but it cannot differentiate the main drivers causing the differences between nations which may be based on population behaviour (influenced by regional values, attitudes and cultural/social norms), accessibility of urban waste management systems, mismanagement of waste, strictness of mask legislation and social distancing/lockdown legislation, all probably contributing to varying degrees among others.

The primary focus of COVID-19 responses have been on human health and reducing impact on society. Our results support other studies in showing the occurrence of a litter problem associated with our human-health focused response. Our results also show intercountry differences in response to to similar COVID-19-related policies. Identifying and understanding interactions among the processes driving litter, especially PPE, should be included in future research and policies, especially as coronavirus-related diseases such as COVID-19 are likely to persist for years to come. Ultimately the differences between nations are probably an artefact from the existing waste management practices and embedded littering behaviours before the pandemic. This will require a combined investment in infrastructure, services and legislation to reduce littering occurrence whilst public PPE use is essential. There is a clear correlation between policies that require the use of masks and their occurrence as litter. As such, future policies should be designed to promote the use of reusable items; facilitate the collection and disposal of single-use items at points where their use is mandatory; and support waste management infrastructure in the recovery and subsequent disposal of the material.

\section{Methods}

Litterati-citizen science data collection. This study used volunteered geographical information already in existence through the English language 
crowd-based, litter collection application Litterati, which has one of the largest databases of tagged litter openly available ${ }^{18}$. Litterati collates data on land-based litter through a mobile phone application populated using volunteer input. Through the free to use application, users upload a geotagged image of the litter they collect which is then categorized through artificial intelligence before being confirmed or amended by the user. Only confirmed tags are added to the item. Over $80 \%$ of uploaded data have been tagged by the community, with over 90,000 unique labels following the format of item description, primary material and brand. The application has around 195,000 active users located in 165 countries, with in excess of 7.8 million pieces of litter uploaded since 2017.

Data selection. Total uploaded litter data were collected from Litterati from the month beginning September 2019 (6 months before the pandemic announcement) to the end of October 2020 for 11 nations with >50,000 unique uploads: the United States (USA), Canada (CAN), the United Kingdom (UK), France (FRA), Germany (DEU), Spain (ESP), Sweden (SWE), Belgium (BEL), the Netherlands (NLD), Australia (AUS) and New Zealand (NZL). Geographic granularity was fixed to a national level to observe the potential impacts of national legislation. Dates and coordinates are available for each item within the Supplementary Information. Collected data were filtered to include only litter that had an assigned tag (for example, plastic bags) producing 2,021,816 tagged individual pieces, with non-tagged/identified items discarded (Supplementary Table 2).

As individuals can tag items as they see fit, this study used generalized terms to identify target litter. Tagged data were further filtered to count all pieces with the term 'mask', 'glove' and 'wipe' in both English and the respective primary language of the nation (Supplementary Table 2), ensuring a maximum count of items. This produced a total count of all collected items, masks, gloves and wipes for each nation and month. The average numbers of unique active users per day were provided by Litterati.

Statistical analysis. Data were expressed as proportions of the total tagged litter for all 11 nations. Kruskal-Wallis non-parametric tests were used to test the following possible conclusions (using $P<0.05$ ):

- The increasing use of PPE due to COVID-19 has led to an increase in their prevalence in litter

- Local legislation on mask use has a greater impact on proportion of masks littered than the WHO advice alone

- Government response in terms of workplace legislation has less impact than mask legislation on the proportion of masks littered

- PPE litter significantly increases due to the announcement of a pandemic

Social distancing status and mask requirement. Data on government response and the level of workplace closing measures were collected using the Oxford University Government Response Tracker ${ }^{24}$. Responses are ranked on a four-point Likert scale, where in all responses essential services and workplaces remained open such as healthcare, logistics and grocery stores, as follows:

1. No advice or requirement, similar restrictions as before COVID-19

2. Recommend closing (or work from home) for all non-essential workplaces where possible

3. Require closing (or work from home) for some non-essential workplaces (for example, theatres and restaurants)

4. Require closing (or work from home) for all but essential workplaces (for example, grocery stores and doctors)

Mask advice per nation data were determined using government sites and the media (Supplementary Information), where either advice or requirement is recorded for all nations ${ }^{50}$. We selected the first instance of advice or requirement within that nation, eliminating devolved decisions (for example, mask use on transport within an individual state or province), ranking these on the following three-point Likert scale:

1. No advice or requirement

2. Advised to wear masks

3. Required to wear masks

Where advice or requirements were announced regionally within a nation, the first instance is used.

\section{Data availability}

All data on litter analysed within this report are available in the Supplementary Information.

Received: 22 December 2020; Accepted: 28 October 2021; Published online: 9 December 2021

\section{References}

1. Canning-Clode, J., Sepúlveda, P., Almeida, S. \& Monteiro, J. Will COVID-19 containment and treatment measures drive shifts in marine litter pollution? Front. Mar. Sci. https://doi.org/10.3389/fmars.2020.00691 (2020).
2. De-la-Torre, G. E. \& Aragaw, T. A. What we need to know about PPE associated with the COVID-19 pandemic in the marine environment. Mar. Pollut. Bull. 163, 111879 (2021).

3. Velavan, T. P. \& Meyer, C. G. The COVID-19 epidemic. Trop. Med. Int. Health 25, 278-280 (2020).

4. Ammendolia, J., Saturno, J., Brooks, A. L., Jacobs, S. \& Jambeck, J. R. An emerging source of plastic pollution: environmental presence of plastic personal protective equipment (PPE) debris related to COVID-19 in a metropolitan city. Environ. Pollut. 269, 116160 (2021).

5. De-la-Torre, G. E., Rakib, M. R. J., Pizarro-Ortega, C. I. \& Dioses-Salinas, D. C. Occurrence of personal protective equipment (PPE) associated with the COVID-19 pandemic along the coast of Lima, Peru. Sci. Total Environ. 774, 145774 (2021)

6. Prata, J. C., Silva, A. L., Walker, T. R., Duarte, A. C. \& Rocha-Santos, T. COVID-19 pandemic repercussions on the use and management of plastics. Environ. Sci. Technol. 54, 7760-7765 (2020).

7. Romney, M. Surgical face masks in the operating theatre: re-examining the evidence. J. Hosp. Infect. 47, 251-256 (2001).

8. Meleney, F. L. \& Stevens, F. A. Postoperative haemolytic streptococcus wound infections and their relation to haemolytic streptococcus carriers among the operating personnel. Surg. Gynecol. Obstet. 43, 338-342 (1926).

9. Fadare, O. O. \& Okoffo, E. D. COVID-19 face masks: a potential source of microplastic fibers in the environment. Sci. Total Environ. 737, 140279 (2020).

10. Advice on the Use of Masks in the Community, During Home Care and in Healthcare Settings in the Context of the Novel Coronavirus (2019-nCoV) Outbreak: Interim Guidance, 29 January 2020 (World Health Organization, 2020).

11. Elachola, H., Ebrahim, S. H. \& Gozzer, E. COVID-19: facemask use prevalence in international airports in Asia, Europe and the Americas, March 2020. Travel Med. Infect. Dis. 35, 101637 (2020).

12. Patel, R. B., Skaria, S. D., Mansour, M. M. \& Smaldone, G. C. Respiratory source control using a surgical mask: an in vitro study. J. Occup. Environ. Hyg. 13, 569-576 (2016).

13. Kolstoe, S. Coronavirus: wearing a cloth face mask is less about science and more about solidarity. The Conversation (20 May 2020); https://theconversation.com/coronavirus-wearing-a-cloth-facemask-is-less-about-science-and-more-about-solidarity-138461

14. Allison, A. L. et al. The impact and effectiveness of the general public wearing masks to reduce the spread of pandemics in the UK: a multidisciplinary comparison of single-use masks versus reusable face masks. UCL Open Environ. https://doi.org/10.14324/111.444/ucloe.000022 (2021).

15. Roberts, K., Bowyer, C., Kolstoe, S. \& Fletcher, S. Coronavirus face masks: an environmental disaster that might last generations. The Conversation (14 August 2020); https://theconversation.com/coronavirus-face-masks-anenvironmental-disaster-that-might-last-generations-144328

16. Haarr, M. L., Westerveld, L., Fabres, J., Iversen, K. R. \& Busch, K. E. T. A novel GIS-based tool for predicting coastal litter accumulation and optimising coastal cleanup actions. Mar. Pollut. Bull. 139, 117-126 (2019).

17. Haarr, M. L., Pantalos, M., Hartviksen, M. K. \& Gressetvold, M. Citizen science data indicate a reduction in beach litter in the Lofoten archipelago in the Norwegian Sea. Mar. Pollut. Bull. 153, 111000 (2020).

18. Litterati (Litterati Open Data, accessed August to November 2020); https://opendata.litterati.org/

19. Rambonnet, L., Vink, S. C., Land-Zandstra, A. M. \& Bosker, T. Making citizen science count: best practices and challenges of citizen science projects on plastics in aquatic environments. Mar. Pollut. Bull. 145, 271-277 (2019).

20. Wu, H.-l., Huang, J., Zhang, C. J., He, Z. \& Ming, W.-K. Facemask shortage and the novel coronavirus disease (COVID-19) outbreak: reflections on public health measures. EClinicalMedicine https://doi.org/10.1016/j. eclinm.2020.100329 (2020)

21. Shortage of Personal Protective Equipment Endangering Health Workers Worldwide (WHO, 2020); https://www.who.int/news-room/detail/0303-2020-shortage-of-personal-protective-equipment-endangering-healthworkers-worldwide

22. Advice on the Use of Masks in the Context of COVID-19: Interim Guidance, 5 June 2020 (World Health Organization, 2020).

23. van der Velde, T. et al. Comparison of marine debris data collected by researchers and citizen scientists: is citizen science data worth the effort? Biol. Conserv. 208, 127-138 (2017).

24. Hale, T., Webster, S., Petherick, A., Phillips, T. \& Kira, B. Oxford COVID-19 Government Response Tracker (OxCGRT, accessed August to November 2020); https://www.bsg.ox.ac.uk/research/research-projects/coronavirusgovernment-response-tracker

25. Elliott, K. C. \& Rosenberg, J. Philosophical foundations for citizen science. Citiz. Sci. Theory Pract. https://doi.org/10.5334/cstp.155 (2019).

26. Bonney, R. et al. Citizen science: a developing tool for expanding science knowledge and scientific literacy. BioScience 59, 977-984 (2009).

27. Stapleton, P. Toxicological considerations of nano-sized plastics. AIMS Environ. Sci. 6, 367-378 (2019). 
28. Sullivan, G., Delgado-Gallardo, J., Watson, T. \& Sarp, S. An investigation into the leaching of micro and nano particles and chemical pollutants from disposable face masks-linked to the COVID-19 pandemic. Water Res. 196, 117033 (2021).

29. Ryan, P. G., Maclean, K. \& Weideman, E. A. The impact of the COVID-19 lockdown on urban street litter in South Africa. Environ. Process. 7 1303-1312 (2020).

30. Okuku, E. et al. The impacts of COVID-19 pandemic on marine litter pollution along the Kenyan coast: a synthesis after 100 days following the first reported case in Kenya. Mar. Pollut. Bull. 162, 111840 (2021).

31. Growing Plastic Pollution in Wake of COVID-19: How Trade Policy Can Help (UNCTAD, 2020); https://unctad.org/news/growing-plastic-pollution-wakecovid-19-how-trade-policy-can-help

32. Singh, J. A. \& Upshur, R. E. G. The granting of emergency use designation to COVID-19 candidate vaccines: implications for COVID-19 vaccine trials. Lancet Infect. Dis. 21, e103-e109 (2020).

33. Rangel, J. C. A way forward: considering the sustainability, equity and unintended effects of social control measures as a response to the COVID-19 crisis. J. Eval. Clin. Pract. https://doi.org/10.1111/jep.13508 (2020).

34. Timlett, R. \& Williams, I. The ISB model (infrastructure, service, behaviour): a tool for waste practitioners. Waste Manag. 31, 1381-1392 (2011).

35. Cialdini, R. B., Reno, R. R. \& Kallgren, C. A. A focus theory of normative conduct: recycling the concept of norms to reduce littering in public places. J. Personal. Soc. Psychol. 58, 1015-1026 (1990).

36. You, S., Sonne, C. \& Ok, Y. S. COVID-19's unsustainable waste management. Science 368, 1438 (2020).

37. Roberts, K. P., Stringfellow, A. M. \& Williams, I. D. Rubbish is piling up and recycling has stalled-waste systems must adapt. The Conversation (30 April 2020); https://theconversation.com/rubbish-is-piling-up-and-recyclinghas-stalled-waste-systems-must-adapt-137100

38. Chin, A. W. H. et al. Stability of SARS-CoV-2 in different environmental conditions. Lancet Microbe 1, e10 (2020)

39. Rangoni, R. \& Jager, W. Social dynamics of littering and adaptive cleaning strategies explored using agent-based modelling. J. Artif. Soc. Soc. Simul. 20, 1 (2017).

40. Arthur, S., Crow, H. \& Pedezert, L. Understanding blockage formation in combined sewer networks. Proc. Inst. Civil Eng. Wat. Manag. 161, 215-221 (2008).

41. Alda-Vidal, C., Browne, A. L. \& Hoolohan, C. "Unflushables": establishing a global agenda for action on everyday practices associated with sewer blockages, water quality, and plastic pollution. WIREs Water 7, e1452 (2020)

42. Williams, A. \& Simmons, S. Estuarine litter at the river/beach interface in the Bristol Channel, United Kingdom. J. Coast. Res. 13, 1159-1165 (1997)

43. Williams, I. \& Deakin, N. Littering of a watercourse in north-west England. Proc. Inst. Civ. Eng. Munic. Eng. 160, 201-207 (2007).
44. Gregory, M. R. Environmental implications of plastic debris in marine settings-entanglement, ingestion, smothering, hangers-on, hitch-hiking and alien invasions. Philos. Trans. R. Soc. B 364, 2013-2025 (2009).

45. Kühn, S. \& Van Franeker, J. A. Quantitative overview of marine debris ingested by marine megafauna. Mar. Pollut. Bull. 151, 110858 (2020).

46. McCauley, S. J. \& Bjorndal, K. A. Conservation implications of dietary dilution from debris ingestion: sublethal effects in post-hatchling loggerhead sea turtles. Conserv. Biol. 13, 925-929 (1999).

47. Kühn, S., Rebolledo, E. L. B. \& van Franeker, J. A. in Marine Anthropogenic Litter (eds Bergmann, M. et al.) 75-116 (Springer, 2015).

48. Lau, W. W. Y. et al. Evaluating scenarios toward zero plastic pollution. Science 369, 1455-1461 (2020).

49. Gasperi, J. et al. Microplastics in air: are we breathing it in? Curr. Opin. Environ. Sci. Health 1, 1-5 (2018).

50. What Countries Require Masks in Public or Recommend Masks? (Masks4All, accessed November 2020); https://masks4all.co/what-countries-requiremasks-in-public/

\section{Acknowledgements}

This research did not receive any specific grant from funding agencies in the public, commercial or not-for-profit sectors. The authors would like to thank the University of Portsmouth Revolution Plastics initiative for supporting the creation of this work and Litterati for their continued support in the development of this research.

\section{Author contributions}

K.P.R. was responsible for conceptualization and methodology. S.E.K. was involved in initial discussions and D.J.H. in supervision. S.C.P. and J.B.W. undertook formal analysis and data curation. I.D.W. was involved in analysis. K.P.R., S.C.P. and J.B.W. contributed to original draft preparation and writing. J.d.B., I.D.W., A.M.S., D.J.H. and S.E.K. contributed to writing, reviewing and editing.

\section{Competing interests}

The authors declare no competing interests.

\section{Additional information}

Supplementary information The online version contains supplementary material available at https://doi.org/10.1038/s41893-021-00824-1.

Correspondence and requests for materials should be addressed to Keiron P. Roberts.

Peer review information Nature Sustainability thanks Justine Ammendolia, Megan Jaunich, Joana Prata and the other, anonymous, reviewer(s) for their contribution to the peer review of this work.

Reprints and permissions information is available at www.nature.com/reprints.

Publisher's note Springer Nature remains neutral with regard to jurisdictional claims in published maps and institutional affiliations.

(c) The Author(s), under exclusive licence to Springer Nature Limited 2021 